Revista Destaques Acadêmicos, Lajeado, v. 9, n. 4, 2017. ISSN 2176-3070

DOI: http://dx.doi.org/10.22410/issn.2176-3070.v9i4a2017.1660

www.univates.br/revistas

\title{
DESENVOLVIMENTO DE CHOCOLATE RECHEADO SEM LACTOSE E SEM GLÚTEN
}

\author{
Cristina Sommer ${ }^{1}$, João Otávio Mezacasa Wollmuth², \\ Maiara Taiana Alexandre ${ }^{3}$, Maíra Spader ${ }^{4}$, Grasciele Tamara Kemerich", \\ Eniz Conceição Oliveira ${ }^{6}$
}

Resumo: A intolerância ao glúten e a lactose são caracterizadas como uma alergia ou sensibilidade que geram condições adversas no sistema digestório, metabólico ou neural de um indivíduo. Tratando-se de uma alergia, o indivíduo tem por restrição a ingestão de proteínas específicas, cujo efeito principal é um ataque ao sistema imunológico, podendo causar diversas reações agressivas, inclusive ataques anafiláticos. Quando tratado como sensibilidade, o sistema imunitário gera condições semelhantes a uma alergia, onde faz-se necessário a substituição parcial ou total na ingestão de determinados alimentos, visando evitar respostas anormais do corpo humano. Seguindo esta linha de estudo, objetivou-se produzir um chocolate benéfico à saúde, livre de lactose e glúten, a fim de proporcionar mais sabor a dietas restritivas. As formulações foram elaboradas com recheio de amendoim, que é fonte de diversos aminoácidos, minerais e vitaminas e grande aliado nas dietas, pois é fonte de ácidos graxos essenciais para a saúde. Durante o desenvolvimento do produto, foram produzidas três formulações de recheio, utilizando leite condensado, outro usando pasta de amendoim e o terceiro uma mistura dos dois componentes, e para todas as formulações o chocolate meio amargo. Para garantia de

1 Graduanda de Química Industrial pela Universidade do Vale do Taquari - UNIVATES, RS. E - mail: csommer@universo.univates.br

2 Graduando de Química Industrial pela Universidade do Vale do Taquari - UNIVATES, RS. E - mail: joaoomw@hotmail.com

3 Graduanda de Química Industrial pela Universidade do Vale do Taquari - UNIVATES, RS. E - mail: maiaratai@hotmail.com

4 Graduanda de Química Industrial pela Universidade do Vale do Taquari - UNIVATES, RS. E - mail: mahspader@hotmail.com

5 Graduada em Química Industrial pela Universidade do Vale do Taquari - UNIVATES, RS. E-mail: gkemerich@universo.univates.br

6 Doutora em Química pela Universidade Federal do Rio Grande do Sul, UFRGS. Professora titular da Universidade do Vale do Taquari - UNIVATES, RS. E-mail: eniz@univates.br 
qualidade do produto foram analisados os teores de cinzas, umidade e proteína bruta, bem como gorduras, atividade de água e $\mathrm{pH}$ das formulações, realizando teste sensorial para determinar a aceitabilidade do produto. A formulação com recheio misto de leite condensado com pasta de amendoim teve maior intenção de compra de 4,5 para uma escala de 1-5. Quanto à possibilidade da disponibilização do produto no mercado, verificou-se pelos resultados das análises que há necessidade da adequação dos teores de umidade, que ultrapassaram os $5 \%$ estipulados como limite pela legislação vigente no país.

Palavras-chave: Chocolate. Glúten. Lactose.

\section{INTRODUÇÃO}

Define-se chocolate o produto preparado com cacau obtido por processos tecnológicos adequados e açúcar, podendo conter algumas outras substâncias alimentícias aprovadas (ANVISA, 1978). Segundo a Agência Nacional de Vigilância Sanitária (ANVISA), o chocolate tem várias classificações, entre elas se encontra o chocolate recheado moldado. É o produto que contém um recheio de substâncias comestíveis, recoberto de chocolate. O recheio deve ser diferente da cobertura, em sua composição. No mínimo $40 \%$ do peso total do produto, deve consistir de chocolate. O produto deve ser denominado chocolate com recheio, seguido da denominação recheio, sendo este, utilizado para este. $\mathrm{O}$ chocolate deve respeitar, assim como qualquer produto alimentício, suas normatizações. Neste trabalho foram feitas análises e comparadas com a Resolução CNNPA n ${ }^{\circ} 12$ de 1978 da ANVISA (ANVISA, 1978). As análises foram de proteínas, que seu valor na legislação não é especificado; lipídeos, que o valor mínimo é de $20 \%$; cinzas, que seu máximo é de $2,5 \%$; umidade com valor máximo permitido de 3\%; pH e AW (atividade de água) não especificados.

Os tipos preferidos de chocolate diferem de um país para outro. $\mathrm{O}$ sabor do chocolate é parcialmente determinado pela composição química do produto; a textura é resultado da maneira como o material se funde e derrete na boca. Alguns produtos têm aromas específicos, gerados pelas mudanças frequentes ocasionadas pelas variações no processo, acidez e temperatura, implicando em variações de aroma e sabor no produto. A composição exata do chocolate varia devido aos diferentes gostos e legislações, que determinam as porcentagens de cacau e sólidos do leite adicionais, quantidade e tipos de gorduras vegetais permitidas (RICHTER; LANNES, 2007). Além de pesquisas para aperfeiçoamento de processos para chocolate, muitos estudos foram feitos nos últimos tempos para criar os mais diferentes tipos e sabores de chocolates, visando sempre à apreciação e necessidade do consumidor. Uma das alternativas para a formulação de novos chocolates destinados aos públicos especiais é a utilização de chocolate sem lactose para pessoas intolerantes a mesma (TRÍADE COMUNICAÇÃO, 2010).

A lactose, que é conhecida como açúcar do leite, é um dissacarídeo formado por glicose e galactose. Esse dissacarídeo é hidrolisado pela enzima 
intestinal lactase, liberando seus componentes monossacarídeos para ser absorvido na corrente sanguínea. A galactose é enzimaticamente convertida em glicose, que é o principal combustível metabólico de muitos tecidos (VOET, 2008). A intolerância à lactose pode ser primária ou secundária. Existe a intolerância, a alergia e a sensibilidade, as quais são constantemente confundidas. A intolerância é uma reação adversa que envolve a digestão ou o metabolismo. A alergia consiste numa resposta do sistema imunitário a componentes alimentares, normalmente proteínas; é quase que exclusivamente limitada aos recém-nascidos. A sensibilidade evidencia-se como uma resposta anormal, por vezes com uma reação semelhante a da alergia (REVISTA ADITIVOS E INGREDIENTES, 2017).

Além da intolerância à lactose, também devemos dar atenção ao público intolerante ao glúten. As principais condições adversas ao glúten que podem vir a ocorrer com o indivíduo saudável, necessitando, portanto de restrição são: a doença celíaca, caracterizada pela intolerância permanente as proteínas do glúten; a alergia ao glúten, a qual é mediada pela imunoglobulina E (IgE); a sensibilidade ao glúten, que é de mais difícil diagnóstico; a ataxia por glúten, marcada por manifestações neurológicas relacionadas à ingestão de glúten; e o controle do Espectro Autista mediante a regulação de ingestão de glúten (WHITELEY et al., 1999). Na presença desta intolerância, os alimentos que contêm glúten devem ser substituídos por outros, como por exemplo: milho, arroz, soja, batata e mandioca, de forma que a dieta atenda às necessidades nutricionais do indivíduo (FARO, 2008; LA BARCA et al., 2010). Nos últimos anos, visando evitar a monotonia das preparações para aqueles que não consomem glúten, inseriu-se novos ingredientes; passaram a ser estudados, inclusive, os derivados do arroz, obtidos no beneficiamento e ainda pouco utilizados na alimentação humana, como é o caso do farelo de arroz (WALTER et al., 2008).

Neste sentido, o objetivo deste trabalho foi desenvolver um chocolate livre de lactose, com recheio de leite condensado sem lactose e pasta de amendoim sem lactose e sem glúten.

\section{MATERIAL E MÉTODOS}

\subsection{Formulação e Produção das Barras de Chocolate}

No desenvolvimento do produto foram utilizados chocolate meio amargo sem lactose para cobertura e para o desenvolvimento do recheio foi utilizado pasta de amendoim sem glúten e leite condensado sem lactose. Foram produzidas três formulações com mesma quantidade de chocolate para cada, variando a concentração dos componentes do recheio. A variação na composição dos recheios pode ser observada na Tabela 1. 
Tabela 1. Ingredientes utilizados nas formulações dos chocolates para 100 gramas de produto

\begin{tabular}{c|c|c|c}
\hline Ingredientes & Formulação A $(\mathrm{g})$ & Formulação B $(\mathrm{g})$ & Formulação C $(\mathrm{g})$ \\
\hline Chocolate & 80 & 80 & 80 \\
\hline Pasta Amendoim & - & 20 & 10 \\
\hline Leite Condensado & 20 & - & 10 \\
\hline
\end{tabular}

Fonte: Autores, 2017.

O desenvolvimento do produto seguiu o procedimento de preparo observado na Figura 1. O chocolate foi derretido em banho-maria e a temperatura do mesmo foi mantida em $31 \pm 1^{\circ} \mathrm{C}$, a fim de obter-se um produto com resistência térmica, brilho, fácil moldagem e prevenção do efeito Fat Bloom (Separação da gordura e formação de superfície esbranquiçada). Durante o processo de produção foi utilizado resfriamento do molde do produto em temperatura de $12^{\circ} \mathrm{C}$, afim de proporcionar o endurecimento das camadas da cobertura sem ocasionar fissuras na camada externa do produto. $\mathrm{O}$ preparo do recheio foi dividido em três seções, uma para cada formulação, onde na primeira formulação somente foi utilizado leite condensado sem lactose, sendo aquecido e resfriado, por três repetições, a fim de obter-se um recheio com característica mais cremosa. Na segunda formulação, onde utilizou-se somente pasta de amendoim, o recheio foi aquecido a $35^{\circ} \mathrm{C}$, afim de reduzir a quantidade de água no produto e tornar mais prático a sua distribuição dentro do molde. $\mathrm{Na}$ terceira formulação, com pasta de amendoim e leite condensado, o recheio foi preparado da mistura, em igual proporção, utilizando aquecimento brando para torná-lo homogêneo e reduzir a umidade, conferindo cremosidade sem perder as características sensoriais advindas da pasta de amendoim. 
Figura 1. Processo de Produção das Barras de Chocolate

\begin{tabular}{|c|}
\hline \multicolumn{2}{|c|}{ Preparo da Cobertura de Chocolate } \\
\hline Derretimento do Chocolate \\
Inserção da Primeira Camada de Chocolate \\
Controle de Peso da Primeira Camada \\
\hline Inserção do Recheio Conforme Formulação \\
\hline Controle de Peso do Recheio \\
\hline Inserção da Segunda Camada de Chocolate \\
\hline Controle de Peso da Segunda Camada \\
\hline \\
\hline
\end{tabular}

Fonte: Autores, 2017.

\subsection{Procedimentos Analíticos}

Foram analisadas as amostras de chocolate meio amargo sem lactose e sem glúten, recheados com leite condensado sem lactose e com pasta de amendoim, estes mantidos sob refrigeração $\left(10^{\circ} \mathrm{C}\right)$ durante 20 minutos. As análises físico-químicas foram realizadas semanalmente em um período de um mês, em triplicatas.

Em torno de $150 \mathrm{~g}$ de cada formulação foi picada e desmanchada em banho maria para facilitar a pesagem das amostras. Após este processo de derretimento começaram-se as pesagens das amostras com o objetivo de verificar as características físico químicas. Essas análises foram realizadas nos Laboratórios da Universidade do Vale do Taquari - UNIVATES.

As determinações de umidade, resíduo mineral, proteína e lipídeos foram realizadas segundo as Normas Analíticas do Instituto Adolfo Lutz (IAL, 2008). A umidade foi determinada por gravimetria a $105^{\circ} \mathrm{C}$ em estufa com circulação de ar. Os resíduos minerais foram determinados por gravimetria com calcinação em mufla a $550^{\circ} \mathrm{C}$. A determinação de proteína seguiu o método Kjedahl. Os lipídeos foram determinados por extração em Soxhlet. A atividade de água foi determinada no equipamento AquaLab e o $\mathrm{pH}$ foi determinado pelo equipamento DIGIMED-Modelo DM- 22.

Avaliou-se a aceitabilidade das amostras, pela análise sensorial, em escala hedônica de nove pontos, com base nos atributos gosta e desgosta, sendo 
9 para gostei extremamente e 1 para desgostei extremamente (MINIM, 2006), analisando-se parâmetros de aparência, odor, textura, sabor e aceitação global.

\section{RESULTADOS E DISCUSSÃO}

A composição centesimal das amostras e resultados de $\mathrm{pH}$ e aw encontram-se na Tabela 2.

Tabela 2. Resultados de composição físico-química das amostras de chocolate.

\begin{tabular}{c|c|c|c}
\hline \multirow{2}{*}{ Análise } & \multicolumn{3}{|c}{ Resultado } \\
\cline { 2 - 4 } & Amostra A & Amostra B & Amostra C \\
\hline Umidade (\%) & 2,91 & 9,90 & 5,95 \\
\hline Lipídios (\%) & 24,70 & 32,70 & 30,70 \\
\hline Cinzas (\%) & 1,20 & 1,13 & 1,83 \\
\hline Proteínas (\%) & 6,70 & 1,13 & 4,90 \\
\hline pH & 7,10 & 7,03 & 7,02 \\
\hline aw & 0,748 & 0,691 & 0,549 \\
\hline
\end{tabular}

Fonte: Autores, 2017. ${ }^{*}$ aw $=$ atividade de água

Os teores de proteínas não são especificados pela resolução CNNPA n ${ }^{\circ} 12$ de 1978 da ANVISA. Os resultados de lipídios e resíduo mineral apresentaramse de acordo com a legislação. O teor de umidade das amostras A e C ficaram acima do permitido (ANVISA, 1978).

O chocolate deve respeitar, assim como qualquer produto alimentício, suas normatizações. Neste trabalho foram feitas análises e comparadas com a Resolução CNNPA n 12 de 1978 da ANVISA (ANVISA, 1978). As análises foram de proteínas, que seu valor na legislação não é especificado; lipídeos, que o valor mínimo é de $20 \%$; cinzas, que seu máximo é de $2,5 \%$; umidade com valor máximo permitido de 3\%; pH e AW (atividade de água) não especificados.

Os 50 questionários, $48 \%$ foram respondidos por homens e $52 \%$ foram respondidos por mulheres. As médias das notas de aceitação em relação aos atributos aparência, odor, sabor, textura e impressão global estão apresentados na Tabela 3, onde se observa que todas as amostras obtiveram médias de aceitação entre 7,0 (gostei moderadamente) e 8,0 (gostei muito), o que comprova boa aceitação do produto.

Comparando os resultados obtidos na análise sensorial com os resultados do trabalho de Trentinalha (2010), que desenvolveram uma trufa isenta de lactose, embora não seja o mesmo produto, ambos tiveram uma boa aceitação mesmo sendo diferenciados do produto tradicional mostrando que a lactose não interfere no sabor. 
Tabela 3. Avaliação sensorial das formulações de chocolate.

\begin{tabular}{l|l|l|l}
\hline & Amostra A & Amostra B & Amostra C \\
\hline Aparência & 7,5 & 7,5 & 7,8 \\
\hline Odor & 7,5 & 7,4 & 7,9 \\
\hline Sabor & 7,1 & 7,8 & 8,0 \\
\hline Textura & 7,4 & 7,9 & 8,0 \\
\hline Impressão global & 7,5 & 8,0 & 8,2 \\
\hline
\end{tabular}

Fonte: Autores, 2017.

A Figura 2 representa os valores obtidos de intenção de compra de cada amostra na análise sensorial.

Figura 2. Intenção de compra das formulações de chocolate produzidas

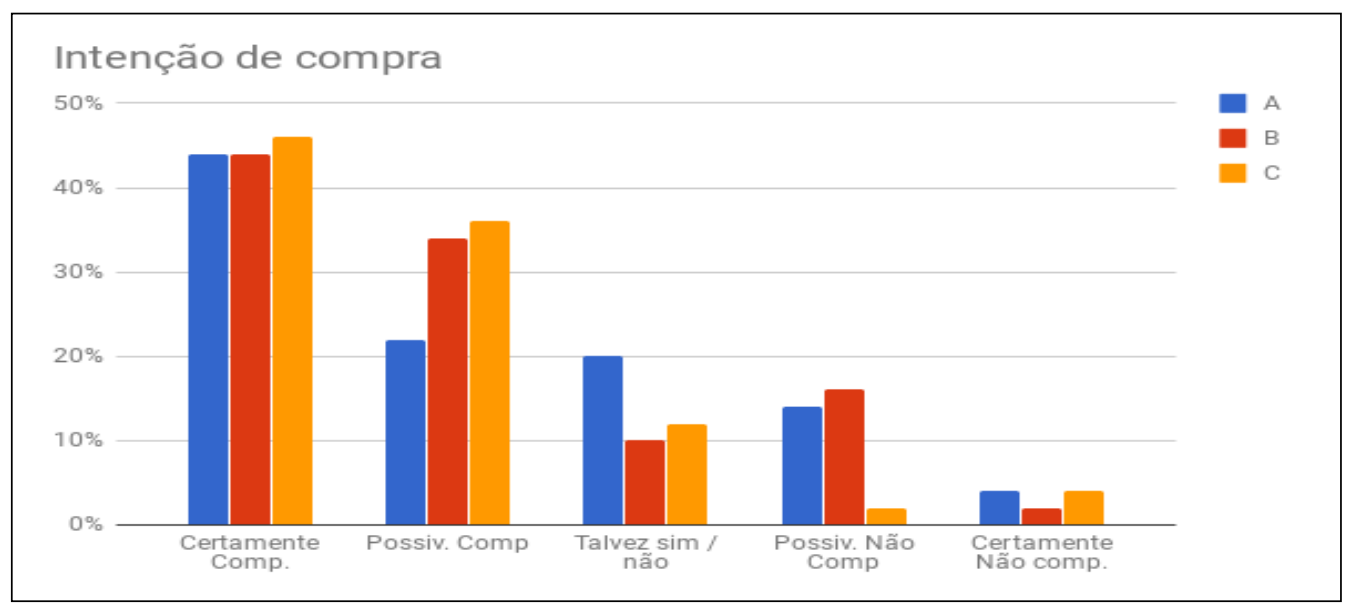

Fonte: Autores, 2017

Observando a Figura 2, pode-se verificar que a formulação $C$ teve maior aceitação entre as três amostras. $\mathrm{O}$ índice de aceitabilidade para a formulação com recheio de pasta de amendoim e leite condensado ficou superior a $85 \%$, valor este próximo ao obtido por Michaelsen e Alves (2017) no desenvolvimento de alfajor sem glúten e sem lactose.

\section{CONCLUSÃO}

Diante dos resultados obtidos, mediante as análises dos produtos, observou-se que perante a legislação vigente para chocolates, as formulações A e C estão acima no quesito umidade (\%), sendo inviável sua comercialização com atual composição. Quanto a apreciação pelos analistas sensoriais, foi 
citado como principal intenção de compra a formulação $C$ que corresponde ao chocolate com recheio misto de pasta de amendoim e leite condensado. Quanto à avaliação negativa do produto, a formulação $\mathrm{A}$, chocolate apenas com recheio de leite condensado, teve menor aceitação pelos avaliadores, mas apresentou $42 \%$ das intenções de compra. Considerando as avaliações das análises, tem-se como objetivo reformular as composições das amostras A e C, reduzindo o teor de umidade, a fim de tornar o produto viável para comercialização.

\section{REFERÊNCIAS}

BRASIL. Agência Nacional de Vigilância Sanitária (ANVISA). Normas Técnicas Especiais Relativas a Alimentos e Bebidas. Resolução CNNPA n 12, de 1978. Diário Oficial da República Federativa do Brasil, 24 de julho de 1978. Disponível em: http:/ / www.anvisa.gov.br/anvisalegis/resol/12_78_chocolate.htm_Acesso em: 08 de novembro de 2017.

FARO, H.C. Doença Celíaca: Revisão Bibliográfica. Monografia (Especialização em Pediatria) Hospital Regional da Asa Sul, Brasília, 2008.

IAL (Instituto Adolfo Lutz). Métodos Físico-Químicos para Análise de Alimentos. Inst. Adolfo Lutz, 4 ed., São Paulo, 2008.

MICHAELSEN, L.K.; ALVES, M.K. Desenvolvimento e Aceitação de Alfajor sem Lactose e Sem Glúten para Dietas com Limitações de Ingredientes. Rev. Brasileira de Prod. Agroindustriais, v.19, n.1, p. 77-82, Campina Grande, 2017.

MAURICIO, A. A.; TRETINALHA A.S. Elaboração e Análise Sensorial de Trufa Isenta de Lactose. Acta Scientiarum. Health Sciences, v 32, n. 1, p. 85-91, Maringá, 2010. Disponível em: http:/ / www.redalyc.org/html/3072/307226626014

RICHTER, M.; LANNES, S.C.S. Ingredientes Usados na Indústria de Chocolates. Revista Brasileira de Ciência Farmacêutica, v. 43, n.3, São Paulo, 2007.

REVISTA ADITIVOS INGREDIENTES. Intolerância a Lactose e Produtos Lácteos com Baixo Teor de Lactose. Disponível em: http:/ /aditivosingredientes.com.br/ http://insumos.com.br/aditivos_e_ingredientes/materias/143.pdf Acesso em: 08 de novembro de 2017.

TRIADE COMUNICAÇÃO. Macadâmia Ganha Mercado e Produtores Investem em Controle de Qualidade. Jornal Agrosoft, Publicação em: 11 de maio de 2010.

VOET, D. Fundamentos de Bioquímica: A Vida em Nível Molecular. Ed. Artmed, 2 ed., 215 p., Porto Alegre, 2008.

WALTER, M.; MARCHEZAN, E.; AVILA, L. A. Arroz: Composição e Características Nutricionais. Ciência Rural, v. 38, n. 4, p. 1184-1192, Santa Maria, 2008.

WHITELEY, P; RODGERS, J; SAVERY, D; SHATTOCK, P. A Gluten-free Diet as an Intervention for Autism and Associated Spectrum Disorders: Preliminary Findings. SAGE Publications and The National Autistic Society. Vol. 3(1) 45-65, 1999. 